\title{
The Protective Effect of Vitamin C on Irradiated Testes of Albino Rat.
}

\author{
Lotfy Sayed*, Esam Eldin Abdel Hady*, Hosam Eldin Hussin*, \\ Atef Ibrahim* and Ola Abdelhamid**
}

\author{
*Departments of Anatomy and Histology, Faculty of Medicine, \\ ALAZHAR University ** Anatomy Department, Faculty of Medicine, \\ ALAZHAR University (Girls)
}

\begin{abstract}
The increased exposure to radiation in medicine or industries increases the hazards of radiation on various organs of the human body.

The aim of this work was to evaluate the protective effect of anti oxidant (vitamin C) against the effect of radiation on rat testes.

Thirty adult albino rats were divided into three groups, each contained ten rats .The first group (G.1) was exposed to $415 \mathrm{r}\left(\mathrm{G} .1^{\prime}\right)$ or $622 \mathrm{r}$ (G.1") using x-ray source for one minute per day for one week. The second group (G.2) was exposed to 415 r (G.2') or 622 r (G.2") using xray source for one minute per day for one week, in addition to vitamin $\mathrm{C}$ equivalent to 86.9 mg./liter orally for the two sub groups for the same period . The third group (G.3) was a control group.

The examined testes of G.1 showed damaged germinal epithelium with remaining some layers of spermatogonia. There was no affection of spermatocytes, mature sperms, Sertoli cells and Leydig cells, the lumen contained little sperms and debris of germ cells (G.1') .While for (G.1") there was marked damage of the seminiferous tubules with irregular outline, destruction of spermatogonia, spermatocytes and spermatids with pyknotic type of nuclear degeneration and the lumen was devoid of mature sperms. The examined testes of the (G.2) showed evidence of almost complete recovery for G .2' and marked recovery for G.2"

It is concluded that anti oxidants were essential to patients exposed to x-ray, to guard against its hazards.
\end{abstract}

\section{Introduction}

There is a considerable interest these days in benevolent chemicals called "free radical scavengers." How well they work is yet to be determined, but population studies strongly suggest that certain diets are better than others, and that those diets are full of free radical scavengers, otherwise known as antioxidants. The recommended ingredients are beta-carotene, vitamins $\mathrm{E}$ and $\mathrm{C}$, and selenium, all available as commercial preparations. Beta-carotene is yelloworange and is present in yellow and orange fruits and vegetables. Vitamin $\mathrm{C}$ can be found naturally in citrus fruits. Vitamin $\mathrm{C}$ is considered as one of the antioxidants used today ,the antioxidants are substances widely used due to their effect to confront the free radicals .(Bast et al. 1991). Vitamin C. is one of biological or naturally available antioxidants.( Krinsky (1992). They produce their scavenger effect by reducing the plasma level of lipid peroxidase and the number of dividing cells, or the micro nucleated cells, also the necrotic or apoptotic effect of the free radicals ( Crott and Fenech, 1999 ).

Radio and television signals, radar, heat, infrared, ultraviolet, sunlight, starlight, cosmic rays, gamma rays, and $\mathrm{x}$ rays all belong to the electromagnetic spectrum and differ only in their relative energy, frequency, and wavelength.The frequencies above visible light have enough energy to penetrate and cause damage to living tissue .The energy of electromagnetic radiation is a direct function of its frequency. The high energy, high frequency waves, which can penetrate solids to various depths, cause 


\section{Lotfy Sayed et al}

damage by separating molecules into electrically charged pieces, a process known as ionization. Atomic particles, cosmic rays, gamma rays, $\mathrm{x}$ rays, and ultraviolet are called ionizing radiation. The pieces they generate are called free radicals Ionizing radiation is so named because each of its units has sufficient energy to eject an orbital electron from an atom and thus produce an ion (electrically charged atom or group of atoms). Examples of ionizing radiation are cosmic ray particles and $\mathrm{x}$ ray or gamma ray photons. (Hewitt et al,. 1980).

The $\mathrm{x}$ ray is widely used type of ionized radiation as a diagnostic tool in medicine; (Charles and Richard King 1994). It produces it's effect by producing a free electron with negative charge ( free radical ) through ionizing the individual atom .( Ackerman et al 1979, Black 1987, Tyrrel and Keyse 1990, Nikjoo et al 1998, Olive 1998, Stewart 2001). The x ray injurious effect resulted from brief and intense exposure (Howell and Shalet 1998). Because radiation is energy, it can be measured. There are a number of units used to quantify radiation energy. Some refer to effects on air, others to effects on living tissue. The roentgen, named after Wilhelm Conrad Roentgen, who discovered $\mathrm{x}$ ray in 1895, measure ionizing energy in air. A rad expresses the energy transferred to tissue. The rem measures tissue response. A roentgen generates about a rad of effect and produces about a rem of response. The gray and the sievert are international units equivalent to 100 rads and rems, respectively. A curie, named after French physicists who experimented with radiation, is a measure of actual radioactivity given off by a radioactive element, not a measure of its effect. The average annual human exposure to natural background radiation is roughly 3 milliSieverts (mSv) (Fauci; 1998). Ionizing radiation has many uses in medicine, both in diagnosis and in treatment. x-ray and CT scanners use it to form images of the body's insides. Nuclear medicine uses radioactive isotopes to diagnose and to treat medical conditions. Radiation can damage every tissue in the body. The particular manifestation will depend upon the amount of radiation, the time over which it is absorbed, and the susceptibility of the tissue. The fastest growing tissues are the most vulnerable, because radiation as much as triples its effects during the growth phase. Bone marrow cells that make blood are the fastest growing cells in the body. The fetus in the womb is equally sensitive. The germinal cells in the testes and ovaries are only slightly less sensitive. Both can be rendered useless with very small doses of radiation. More resistant are the lining cells of the body--skin and intestine. Most resistant are the brain cells, because they grow the slowest. The relative sensitivity of various tissues gives a good idea of the wide range that presents itself. The numbers represent the minimum damaging doses; a gray and a sievert represent roughly the same amount of radiation:

- Fetus--2 grays (Gy).

- Bone marrow--2 Gy.

- Ovary--2-3 Gy.

- Testes--5-15 Gy.

- Lens of the eye--5 Gy.

- Child cartilage--10 Gy.

- Adult cartilage--60 Gy.

- Child bone--20 Gy.

- Adult bone--60 Gy.

- Kidney--23 Gy.

- Child muscle--20-30 Gy.

- Adult muscle--100 Gy.

- Intestines--45-55 Gy.

- Brain--50 Gy. (Fauci; 1998).

The pathological anatomy of $\mathrm{x}$ ray resulted from three main types; necrosis, infection and hemorrhage (Charles and Richard King 1994). Gonad irradiation can cause genetic defects that may be passed on to future generations ( HEW. 1976) .When the testes are exposed to radiation, sperm count begins to decrease and, depending on the dosage and may result in temporary or permanent sterility Yarbro and Perry, (1995), Damani, et. al.(2002). Men who receive radiation to the abdominal or pelvic region may still regain partial or full sperm production depending on the amount of injury to the testes. Unlike the germinal epithelium, Leydig cells function may be 
more prone to damage from irradiation in prepubertal life than in adulthood Ward, (1988) , Barendsen , (1994) , Cross, (1994), Khan, et. al. (1995), Howell and Shalet, (1998) and Thierens, et. al. (1999). Exposing the testes to ionizing radiation at a dose below 6 Gy causes disturbances of spermatogenesis and altered spermatocytes with recovery periods dependent on dose ;(Yarbro and Perry; 1995) .Doses above 6 Gy cause permanent infertility by killing off all stem cells. For women, a dose of 5 Gy to 20 Gy administered to the ovary is sufficient to completely impair gonadal function regardless of the patient's age; a dose of 30 Gy provokes premature menopause in $60 \%$ of women younger than 26 years of age , Donnez and Bassil,( 1998),Ragni, et. al.(2003), Schrader M, et. al. (2003).

A live born child, conceived after radiation exposure of one or both parents, is considered to be at risk of inheriting one or more radiation induced genetic defects. From each parent's exposure, we assume a risk coefficient of 3 in $1,000,000$ per millisievert (BEIR 1990). The total risk to a child is approximately the sum of the risks from the mother and father In the general population, about 23 percent (200 to 300 in $10,000)$ of the children are born with serious anatomic abnormalities (UNSCEAR 1986. and BEIR 1990).

\section{Material and Method}

Thirty adult albino rats were divided into three groups, each group contained ten rats. The first group; (G.1) was exposed to 415 r (G.1') or 622 r (G.1") using x-ray source for one minute per day for one week. The second group; (G.2) was exposed to 415 r (G.2') or 622 r (G.2") using x-ray source for one minute per day for one week , in addition to vitamin $\mathrm{C}$ equivalent to 86.9 $\mathrm{mg}$./liter orally for the two sub groups for the same period. The third group (G.3) was a control group.

The three groups were maintained on a well balanced diet containing wheat bread, carrot, alfalfa and milk, water was provided at libitum. This diet did not produce morphological or functional changes in the rats. The animals were sacrificed after the designated time .The testes were extracted and prepared for histological and E/M examination.

\section{Results}

The examined testes of the first group, (G.1):

(G.1') showed damaged germinal epithelium with remaining some layers of spermatogonia but there was no affection of spermatocytes, mature sperms, Sertoli cells and Leydig cells. The lumen contained little sperms and debris of germ cells (Fig. $8)$.

(G.1") showed marked damage of the seminiferous tubule with irregular outline, destruction of spermatogonia, spermatocytes and spermatids with pyknotic type of nuclear degeneration and the lumen was devoid of mature sperms (Fig . 9).

The examined testes of the second group, (G.2):

(G .2')showed evidence of almost complete recovery of the seminiferous tubules ,they regained the regular arrangement of the germ cells, the lumen contained little sperms and the empty spaces were diminished due to regeneration of germ cells (Fig . 10)A \&B .

(G .2") showed evidences of some degree of recovery of the seminiferous tubules with the presence of spermatogonia and spermatocytes, the lumen contained some sperms (Fig. 11) A \&B.

Fig (1): An electron micrograph of the control rat showing primary spermatocyte with nucleus (n) and eccentric nucleolus $(\rightarrow)$. The cytoplasm shows dispersed mitochondria and endoplasmic reticulum. $\quad \mathrm{X} 8000$

Fig (2): An electron micrograph of the control rat showing; T.S. in seminiferous tubules, Basement membrane $(\rightarrow)$.Sertoli cell with indented nucleus (S) .Spermatogonia (G) .Spermatocyte ( PS ).Spermatid (D) . X6400 


\section{Lotfy Sayed et al}

Fig (3): An electron micrograph of a treated rat showing: Spermatocyte (PS); with eccentric nucleus, mitochondria were arranged in a periphery .Spermatid (D) had nucleus with spermatic cape, spermatic vesicle and mitochondria arranged in periphery .There are deformed sperms $(\rightarrow)$.The intercellular spaces are widen. $\quad$ X8000

Fig (4): An electron micrograph of a treated rat showing: normal Spermatid (D) in different sections, the head of the spermatid shows irregularity and degeneration .Increased intercellular spaces $(\rightarrow)$ X3200

Fig (5): An electron micrograph of a treated rat showing: T.S. in seminiferous tubule with: 1-The tubules have Sertoli cell with indented nuclei ( $\mathrm{S}$ ) 2-Degenerated spermatocytes 3Spermatids (D ) .4-Wide intercellular spaces $(\rightarrow)$.

X6400

Fig (6): Section of control rat testes Showing: layers of germ cells $(G)$ .Sperms in the lumen $(\mathrm{P})$.

Iron hematoxylin $\mathrm{x} 400$.

Fig (7) : Section of control rat testes showing part of a seminiferous tubules with spermatogonia ( Ad ) .primary spermatocytes ( C ).Sperms (P) . Sertoli cell (T) and Blood vessels.

H\&E x 1000.
Fig (8): Section of irradiated rat testes $(G$ .1 ) showing: 1-Seminiferous tubule with highly affected spermatogonia. 2-debris of germ cell could be observed $(\rightarrow)$. 3- Large vacuoles.

$$
\mathrm{H} \& \mathrm{E} \times 400
$$

Fig (9): section of irradiated rat testes (G.

1") showing: 1- Spermatogonia (Ad) with irregular arrangement 2-Primary spermatocytes (C) 3-Well developed sperms (P) 4-Empty spaces $(\rightarrow)$.

H\&E x 1000

Fig (10): Section of irradiated rat testes (G.

2') showing almost complete recovery; 1-The seminiferous tubules regained their normal appearance and arrangement of the germ cells 2The lumen contained some sperms.

A- H\&E x 400

B- H\&E x 1000

Fig (11): Section of irradiated rat testes (G. 2") containing seminiferous tubule with: 1-Layer of spermatogenic cells detached from the basement membrane $(\rightarrow) \quad$ 2-The lumen contains debris of sperms and degenerated materials.

A- Iron hematoxylin. x 200

B- Iron hematoxylin $x 400$ 


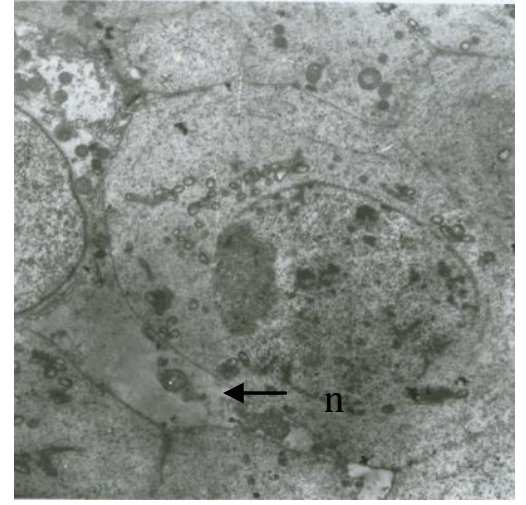

Fig (1)

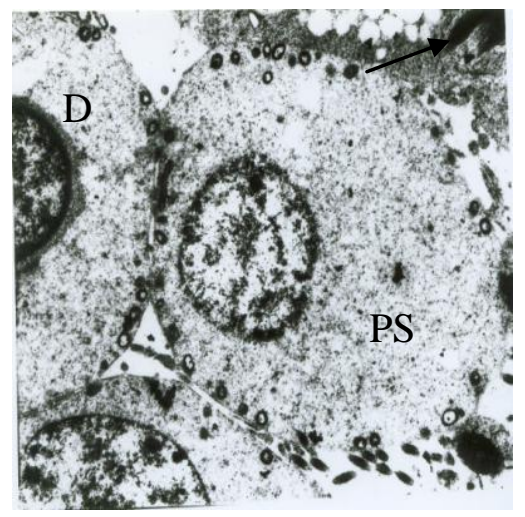

Fig (3)

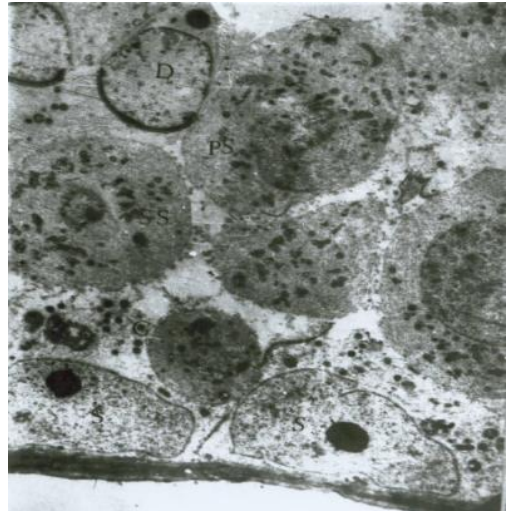

Fig (2)

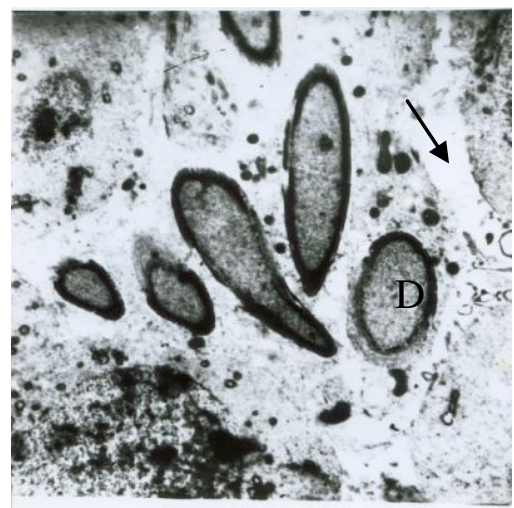

Fig (4)

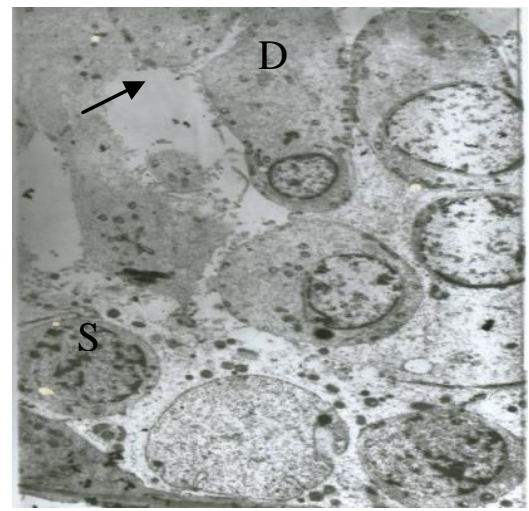

Fig (5) 


\section{Lotfy Sayed et al}
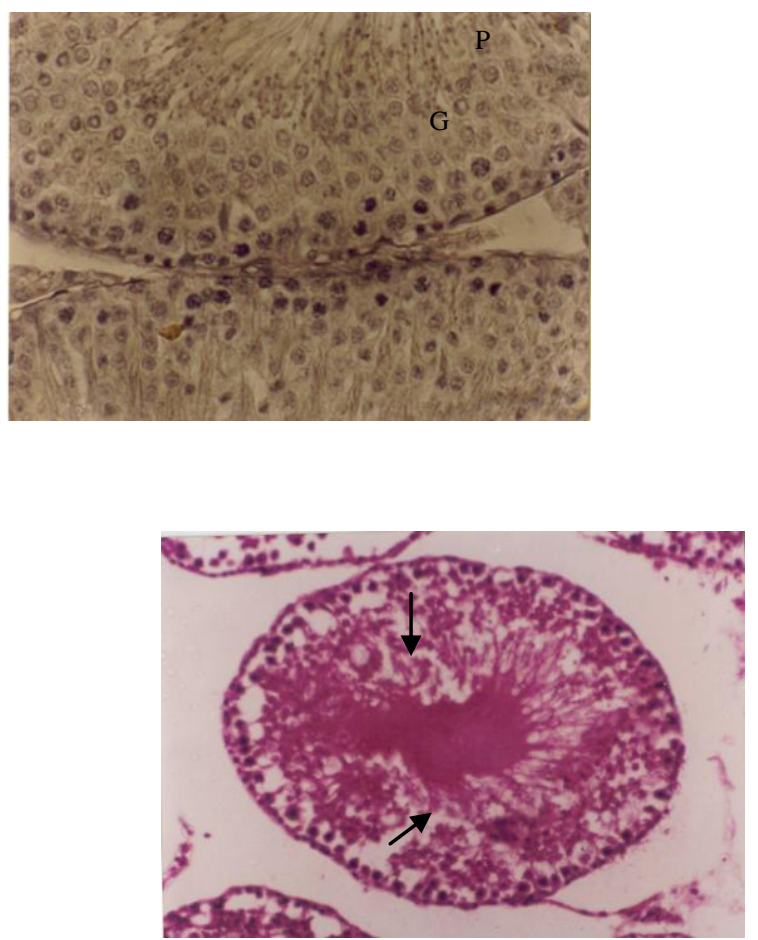

Fig (8)

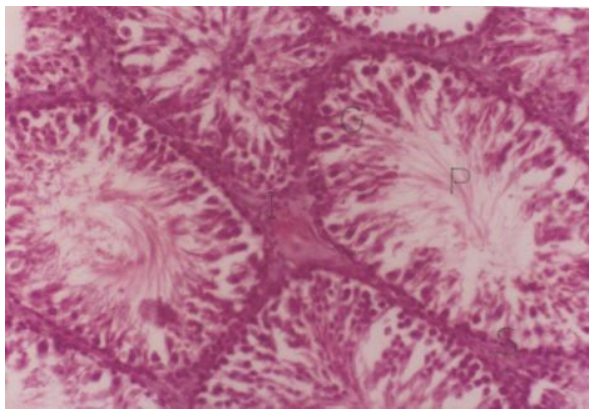

Fig (10) A

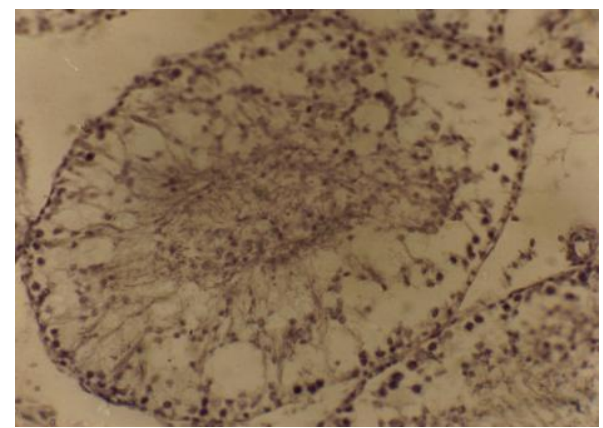

Fig (11) A
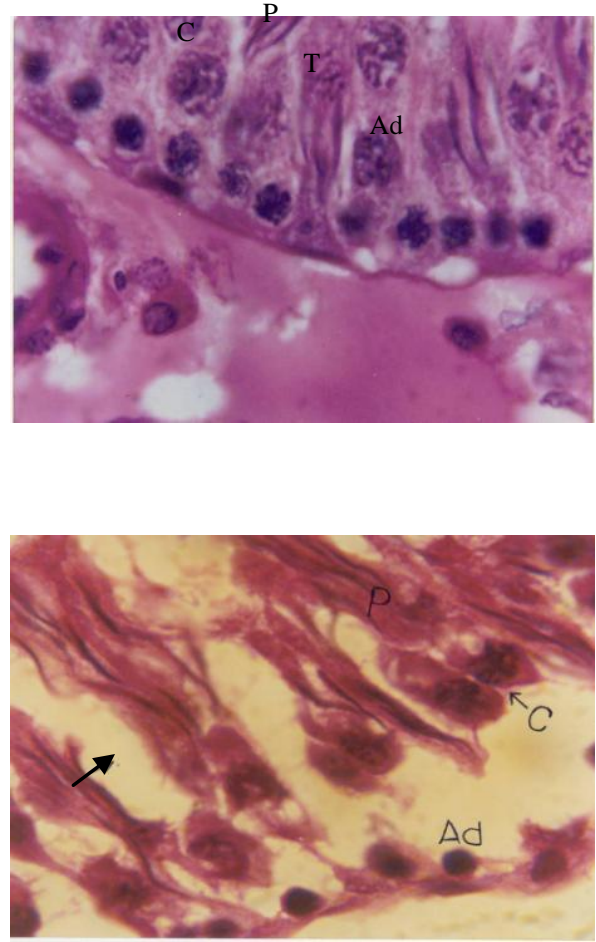

Fig (9)

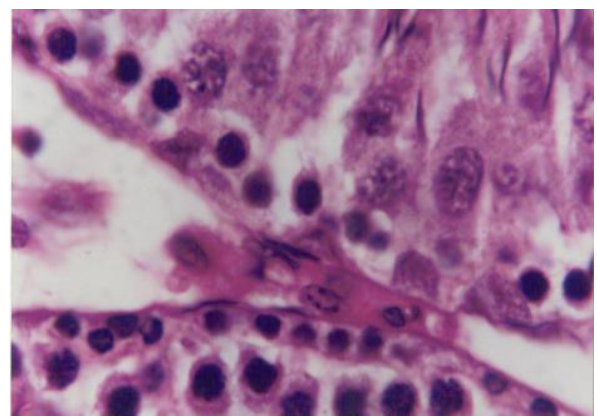

Fig (10) B

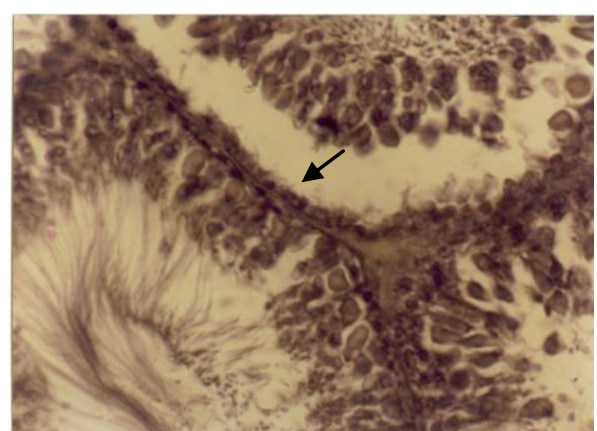

Fig (11) B 


\section{Discussion}

The selection of testes as a target organ was due to The easy extraction and preparation of the testes to either light and E/M. examination, also due to the expected obvious effect of radiation hazards on the rapidly dividing cells, (the testes) as they were among the more radiosensitive organs in the body (Tullis, 1989). The x ray type of radiation was selected for this study due to its wide use in medicine as a diagnostic tool(Charles and Richard King 1994). Also It belongs to the electromagnetic spectrum as one of the ionizing radiation which causes free radicals (Hewitt et al 1980). Moreover its injurious effect resulted from brief and intense exposure (Howell and Shalet 1998).

The use of vitamin $\mathrm{C}$ as a natural source antioxidant was due to its wide and easy source of anti oxidants (Krinsky (1992). Also it is used due to its ability to confront the free radicals. (Bast et al. 1991).

The destruction of the spermatogonia detected in this study was agreed with data proved by Ward, (1988), Barendsen, (1994), Cross, (1994), Khan, (1995), Howell and Shalet , (1998) and Thierens, et. al. (1999).

Absence of sperms in the irradiated group agreed with results obtained by Yarbro and Perry; (1995).

The recovery detected in group 2 was agreed with results approved by Yarbro and Perry. (1995).

\section{References}

1. Ackerman, E. Elie, L. and Williams, I. (1979): Biophysical science, 2 ed. Chapter 17. Prentice Hall Inc., New Jersey pp.306319.

2. Barendsen, G.W (1994). Relationships for different types of lethal radiation damage in mammalian cells: comparison with DNA $\mathrm{dsb}$ and an interpretation of differences in radio sensitivity. Int. J. Radiat. Biol., 66(5), 433-436

3. Bast, A. Haenen, G. and Doelman, C. (1991): Oxidants and antioxidant; State of the Art. Am .J. med.; 91(suppl.3c); 25.
4. BEIR (1990). Committee on the Biological Effects of Ionizing Radiations. Health Effects of Exposure to Low Levels of Ionizing Radiation. BEIR V. Washington, D.C.: National Academy Press.

5. Black, C. (1987): Phto carcinogenesis and diet. Fed. Proc. 145:83-86.

6. Charles, F. and Richard king, E. (1994): Atomic Medicine.4th.edi.The Williams and Wilkins company, Baltimore. 1994. pp 86107.

7. Cross,F.T (1994). Invited commentary: Residential radon risks from the perspective of experimental animal studies. American J. of Epidem. 140:333-339,

8. Crott, J. And Fenech, K. (1999): Effect of vitamin C supplementation on chromosome damage, apoptosis, and necrosis ex vivo .Carcinogenesis. 1999. jun. 20(6):10351076

9. Damani, M., Master, V. and Meng, M. (2002.): Post chemotherapy ejaculatory azoospermia: fatherhood with sperm from testis tissue with intracytoplasmic sperm injection. J. Clin. Oncol. 20 (4): 930-6,

10. Donnez J, Bassil S (1998) Indications for cryopreservation of ovarian tissue. Hum Reprod Update 4 (3): 248-59, May-Jun.

11. Fauci,AnthonyS.,et al., (1998) . Harrison's Principles of Internal Medicine. 14th Ed. New York: McGraw-Hill,

12. Hewitt, J.E., L. Hughes, J.B. Mc Caslin, A.R. Smith, L.D. Stephens, C.A. Syvertson, R.H. Thomas and A.B. Tucker (1980). Exposure to Cosmic Ray Neutrons at Commercial Jet Aircraft Altitudes. In: Natural Radiation Environment III, Symposium Proceedings, Houston, TX, April 2328, 1978.

13. HEW (1976). U.S. Department of Health, Education, and Welfare; PHS; Food and Drug Administration; Bureau of Radiological Health. Gonad Doses and Genetically Significant Dose from Diagnostic Radiology: U.S., 1964 and 1970. HEW Publication (FDA) 768034. Rockville, MD. NTIS PB254173. (See p. 3; p. 21, table 55; p. 22.)

14. Howell, S., Shalet, S. (1998): Gonadal damage from chemotherapy and radiotherapy. Endocrinol Metab Clin North Am 27 (4): 927-43.

15. Khan, M Cross, R, Bushbom, and A. Brooks, (1995). Inhaled radon induced genotoxicity in Webster rat, Syrian hamster, and Chinese hamster deeplung 


\section{Lotfy Sayed et al}

fibroblasts in vivo. Mutat. Research. 334:131-137.

16. Krinsky, N. (1992): Mechanism of action biological antioxidant .Proc. Soc. Exp. Bio. Med., 2001 Sep. 1; 480:85-95.

17. Nikjoo, H. Uchaa, S. Wison, E. Hoshi, M. and Goodhead, T. (1998): Track structure in radiation theory and application. Int. j. radiat. Bio. 73,4 , p. $355-358$

18. Olive, P. (1998): The roll and DNA single -and double strand breaks in cell killing by ionization. Radi. Res. 150, 5,542-551.

19. Ragni G, Somigliana E, and Restelli L, et al., (2003): Sperm banking and rate of assisted reproduction treatment: insights from a 15-year cryopreservation program for male cancer patients. Cancer 97 (7): 1624-9.

20. Schrader M, Mller M, Sofikitis N, et al (2003).: "Onco-tese": testicular sperm extraction in azoospermic cancer patients before chemotherapy-new guidelines? Urology 61 (2): 421-5,

21. Stewart, R. (2001): Tow lesion Kinetic model of DSB rejoining and Killing. Radia. Res. June, 25,341-235.

22. Thierens, A. Vral, L. DeridderE, N. Touil, M. Kirsch-Volders, V. Lambert,
C. Lauren(1999).. Inter-laboratory comparison of cytogenetic endpoints for the biomonitoring of radiological workers. Int. J. Radiat. Biol. 75: 23-34

23. Tullis, J. (1989): Atomic Medicine. $4^{\text {th }}$ ed. Charles, F. and Richard King, E. Williams and Wilkins company Baltimore pp.138169.

24. Tyrrel, R. and Keyse, M. (1990): New trend in photobiology. The interaction of UVA radiation with cultured cell. J. photochem. Photobiol. B, 4(4); 349-361.

25. UNSCEAR (1986). United Nations Scientific Committee on the Effects of Atomic Radiation. Genetic and Somatic Effects of Ionizing Radiation. Annex C: Biological effects of prenatal irradiation. New York: United Nations. (See p. 338.)

26. Ward, J. (1988): DNA damage produced by ionizing radiation in mammalian cells: identities, mechanisms of formation, and reparability. In Progress in Nucleic Acid Research, 35, p. 95-125..

27. Yarbro CH, and Perry MC, (1995): The effect of cancer therapy on gonadal function. Semin Oncol Nurs 1 (1): 3-8. 


\section{التأثير الوقائي لفيتامين (ج) على الخصية المشععة للجرذ الأبيض \\ لطفي سيد*؛ عصام الدين عبد الهادي*؛ حسام الدين حسين*؛ عاطف إبراهيم*

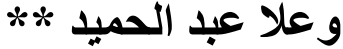 \\ قسمى التشريح و الهستولوجى* ـ ـلية الطب الطب بنين - جامعة الأزهر. \\ قسم التنريح ** ـ كلية الطب بنات - جامعة الأزهر}

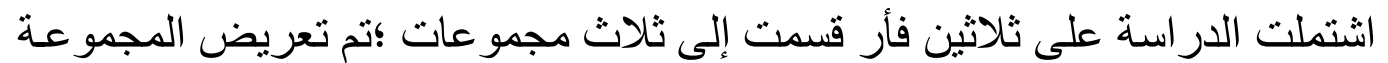

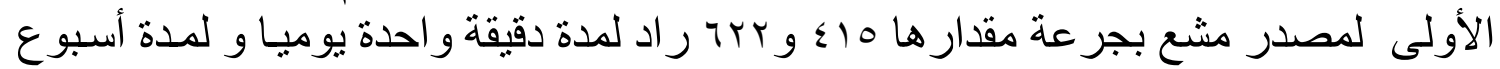

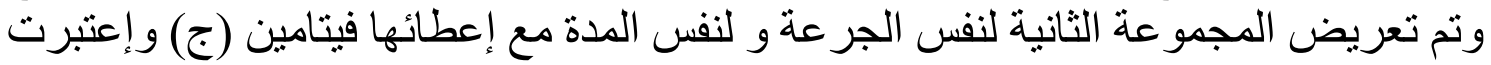

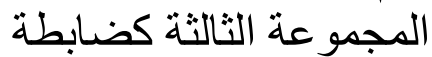

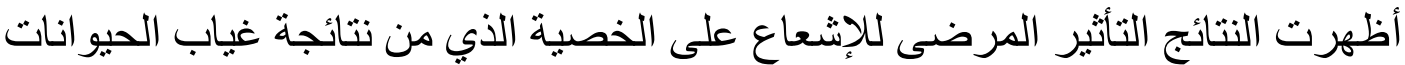

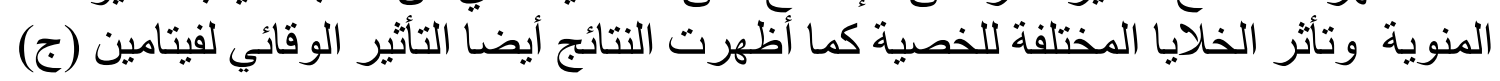

